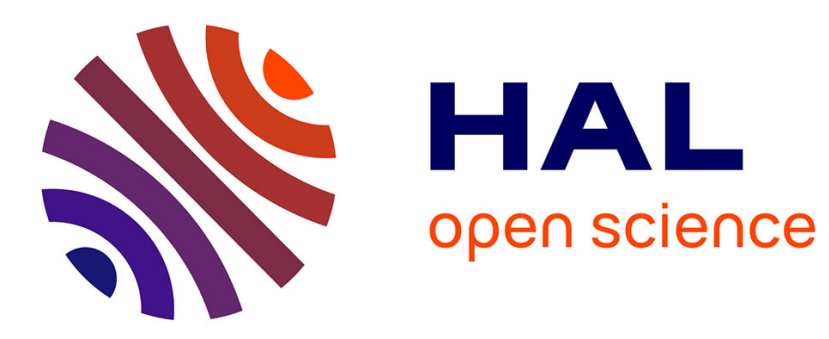

\title{
The sense of agency: A philosophical and empirical review of the "Who" system
}

\author{
Frédérique de Vignemont, Pierre Fourneret
}

\section{To cite this version:}

Frédérique de Vignemont, Pierre Fourneret. The sense of agency: A philosophical and empirical review of the "Who" system. Consciousness and Cognition, 2004, 13, pp.1-19. ijn_00169846

\section{HAL Id: ijn_00169846 \\ https://hal.science/ijn_00169846}

Submitted on 5 Sep 2007

HAL is a multi-disciplinary open access archive for the deposit and dissemination of scientific research documents, whether they are published or not. The documents may come from teaching and research institutions in France or abroad, or from public or private research centers.
L'archive ouverte pluridisciplinaire HAL, est destinée au dépôt et à la diffusion de documents scientifiques de niveau recherche, publiés ou non, émanant des établissements d'enseignement et de recherche français ou étrangers, des laboratoires publics ou privés. 


\title{
The sense of agency: A philosophical and empirical review of the "Who" system
}

\author{
F. de Vignemont ${ }^{\mathrm{a}, *}$ and P. Fourneret ${ }^{\mathrm{b}}$

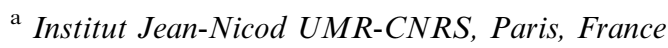 \\ ${ }^{\mathrm{b}}$ Institut des Sciences Cognitives, UMR-CNRS 5075, Bron, France
}

Received 6 December 2002

\begin{abstract}
How do I know that I am the person who is moving? According to Wittgenstein (1958), the sense of agency involves a primitive notion of the self used as subject, which does not rely on any prior perceptual identification and which is immune to error through misidentification. However, the neuroscience of action and the neuropsychology of schizophrenia show the existence of specific cognitive processes underlying the sense of agency - the "Who" system (Georgieff \& Jeannerod, 1998) - which is disrupted in delusions of control (Frith, 1992). Yet, we have to be careful in the interpretation of such clinical symptoms, which cannot be so easily reduced to deficit of action monitoring or to lack of action awareness. Moreover, we should refine the definition of the sense of agency by distinguishing the sense of initiation and the sense of one's own movements. A conceptual analysis of the empirical data will lead us to establish the taxonomy of the different levels of action representations.
\end{abstract}

(C) 2003 Elsevier Science (USA). All rights reserved.

Keywords: Self; Agency; Action monitoring; Action awareness; Neuropsychology; Philosophy of mind; Delusions of control

\section{Introduction}

How can I know myself? The self is elusive and always seems to escape from introspection. As Hume (1739) noticed, when I look deep into myself, I only find "a bundle of perceptions," but I

\footnotetext{
${ }^{*}$ Corresponding author. Present address: Institut des Sciences Cognitives, 67 bd pinel, 69675 Bron.

E-mail address: vignemo@isc.cnrs.fr (F. de Vignemont).
} 
never find the self. Thus, the question is to know whether self-consciousness can be reduced to the consciousness of this bundle of perceptions. In other words, how do I recognize my mental and bodily states as mine? For instance, when I am aware that I am running I am conscious of: (1) the action of running and (2) the person who is running, that is, me. We'll suggest here that these two aspects are distinct and that the sense of agency-defined as the ability to refer to oneself as the author of one's own actions - depends on specific cognitive and neural processes that need to be investigated. The notion of self involved here is primitive and we will not address the metaphysical question of its nature, its reality or its fictional character. Rather, we intend to sketch the cognitive conditions underlying the sense of agency by integrating the recent empirical data of neuroscience and neuropsychology and the conceptual analysis of philosophy.

\section{2. "I-thoughts"}

I have a car, I'm tall, I move my arm, I'm thinking, I feel angry. . . I can self-ascribe a quasiinfinite list of predicates. What is common to all these propositions (or I-thoughts) is the subject to whom the properties are attributed, the reference of "I". However, the presence of the first person concept is not sufficient to make this category of I-thoughts homogeneous. Indeed, they do not have the same causal history nor do they have the same epistemic status.

\subsection{Two kinds of I-thoughts}

I see a tree. But how do I know that I am the person who sees the tree? Shoemaker (1963) asked. When Jones sees a tree, the fact that I see Jones seeing the tree justifies my conclusion that he is the person who sees the tree. However, it would be nonsensical to suggest that similarly I see myself seeing the tree. I do not need either to know who I am to recognize this visual experience as mine. Self-attributions of occurring mental states do not use criteria of personal identity: Even if I am an amnesiac, I know that I see a tree. Consequently, this kind of I-thoughts does not depend on any perceptual or semantic identification of the subject. On the contrary, other I-thoughts require identifying myself as the person who is described. In this latter case, I cannot assert, "I am F.V." if I have no information about myself. Similarly, in order to recognize myself in the mirror, I need to identify the person that I am looking at as myself. The distinction between these two types of I-thoughts does not arise from the kind of property ascribed (for instance, mental versus bodily properties), but rather from the way of gaining self-knowledge (Evans, 1982). Thus, the very same property can be self-attributed following different ways of knowing: Some depend on the identification of the subject whereas others are identification-free.

For instance, bodily self-knowledge may be based on visual information ("I see my arm raising") or on proprioceptive information ("I feel my arm raising"). The former case involves a prior visual identification ("The arm that I see is mine"). As I can see my own body as well as the body of other people, I need to distinguish them. On the contrary, the latter case is identification-free and directly relies on my proprioceptive system. As I cannot receive any proprioceptive information about someone else's body, I am assured that the source of the information is my own body (Evans, 1982). Consequently, proprioceptive self-ascriptions do not depend on the identification of the body as one's own, unlike visual self-ascriptions of bodily properties. Following 
Wittgenstein (1958, pp. 66-67) we should thus distinguish the first person used as subject and the first person used as object:

There are two different cases in the use of the word 'I' (or 'my') which I might call 'the use as object' and the 'use as subject' (...). The cases of the first category involve the recognition of a particular person, and there is in these cases the possibility of an error (...). On the other hand, there is no question of recognizing a person when I say I have a toothache. To ask 'are you sure that it's you who have pains?" would be nonsensical.

Identification implies ipso facto the possibility of misidentification: I may wrongly believe that I am the person in the mirror, when it is actually my twin. On the contrary, the I-thoughts that are identification-free are said to be "immune to error through misidentification" (Shoemaker, 1994): I cannot believe that I am thinking while it is actually someone else who is thinking. Nonetheless, I may still falsely believe that I am thinking while I am actually sleeping. We need here to distinguish two kinds of errors in self-knowledge: At the level of the self-ascribed property ("I have blond hair," while I am actually dark-haired) and at the level of the subject to whom the property is ascribed ("My stomach is groaning," while it is actually my neighbor's one). The principle of immunity to error concerns only the level of the subject. It assumes that the asymmetry between the knowledge of one's own mind and the knowledge of other minds is such that one could never confuse one's own thoughts with someone else's thoughts. For instance, as soon as I know the bodily property on the basis of internal information such as proprioception, I would be assured that the body that I feel is mine. Similarly, I would have a privileged access to my own actions that I do not have for the actions performed by other people. Thus, as soon as I know the action from the first person perspective of the agent, I would be assured that I am the person who is moving.

\subsection{The fallibility of self-attribution}

However, we have to make a distinction between the fact that I own a certain state - mental or bodily - and the fact that I recognize this state as mine. Roughly, we should not conflate the objective relation of belonging and the epistemic relation of self-attribution. For instance, patients suffering from asomatognosia following a right parietal lesion deny the ownership of their limb controlateral to the brain lesion and attribute the 'alien hand' to someone else or personify it, as in the following example (Bisiach, Rusconi, \& Vallar, 1991, p. 1030):

Examiner: Whose arm is this?

A.R.: It's not mine.

Ex: Whose is it?

A.R.: It's my mother's.

Ex: How on earth does it happen to be there?

A.R.: I don't know. I found it in my bed.

Ex: How long has it been there?

A.R.: Since the first day. Feel, it's warmer than mine. The other day too, when the weather was colder, it was warmer than mine.

Ex: So, where is your left arm?

A.R.: It's under there (indefinite gesture forwards) 
Even if this disorder is frequently associated to hemianaesthesia and unilateral neglect, it is independent from sensory deficits: A patient may scream when her 'alien hand' is squeezed, but still denies that this hand belongs to her (Melzack, 1992). Similarly, Bottini, Bisiach, Sterzi, and Vallar (2002) described the case of F.B., a patient who attributed her hand to her niece. She was able to report a tactile sensation only if she was previously warned that her niece's hand was going to be touched. The authors concluded that somatosensory representations do not suffice for recognizing a body part as one's own. We may then wonder about the nature of the cognitive conditions of the sense of ownership of one's own body.

Consequently, far from being absolute, the immunity to error is only circumstantial because it depends on the reliability of the way of gaining self-knowledge (Evans, 1982). In other words, the fact that some I-thoughts do not depend on any identification does not imply that they do not depend on any causal process, which can be fallible. This conclusion is valid not only for the sense of ownership, but also for the sense of agency of one's own actions. We'll see in the next part that the border between the self and the other is sometimes so dim that one can misattribute one's own actions to someone else and vice-versa. I may indeed mistakenly believe that my arm is moving because I perceive an arm in movement. Action misattribution would thus result from body misattribution. However, we should not reduce the sense of agency to the sense of ownership of one's own body despite the wide importance of their interactions (Gallagher, 2000). An action is not only perceived, it is also initiated, controlled and inhibited. We have thus to take into account the dimension of the agent who is the cause of the action. In this sense, I may indeed not be the agent of all my bodily movements like in passive movements when for instance someone else raises my arm for me. It is only in a derivative sense that passive movements are mine because all I own in theses cases is the moving body. Therefore, we can raise the following question: what must be added to the neutral state ("Performed action") to be able to self-ascribe it ("I am moving")?

In summary, we have two different kinds of I-thoughts using different notions of the self. When I recognize the action of grasping a glass as my own, the sense of agency involves the notion of a "minimal self" (Gallagher, 2000), which is instantaneous and which carries only one bit of information about myself, that is, that I am grasping a glass. On the contrary, the knowledge that I am the person in the mirror depends on recognitional criteria that allow me to reidentify myself through time. The notion of the "recognitional self" has a richer content and may even constitute personal identity. In this paper, we do not intend to address the whole issue of I-thoughts, but only to focus on the minimal self involved in agency. In other words, how am I aware that I am the agent who is moving?

\section{A neurocognitive model of action consciousness and agency}

The sense of agency involves a primitive notion of the self used as subject, which does not rely on any prior perceptual identification and which is immune to error through misidentification. However, we are going to see that the neuroscience of action and the neuropsychology of schizophrenia show the existence of specific cognitive processes underlying the sense of agency_the "Who" system (Georgieff \& Jeannerod, 1998)—which would be disrupted in delusions of control (Frith, 1992). 


\subsection{The necessity of the "Who" system}

This behavior [the syndrome of compulsory imitation] suggests that an observer monitoring an action performed by someone else is never far from being also the agent of that action. (Jeannerod, forthcoming)

Following frontal lesions, some patients automatically execute the action performed by someone else that they are observing, losing track of the distinction between their own intentions and the intentions of others (Lhermitte, Pillon, \& Serdaru, 1986). More generally, imitation constitutes a "bridge" that carries interpersonal information and plays a major role in the interaction between people starting from birth. For instance, neonates are able to imitate finger movements and facial expressions such as tongue protrusion (Meltzoff \& Moore, 1995). In this latter case, the infant has to match visual information about someone else and proprioceptive information about himself. Thus, imitation implies "innate mappings from self to others" (Gopnik \& Meltzoff, 1994, p. 168) and can be understood only if we postulate the existence of shared representations of action between the imitator and its target. Rather than focusing on the gap between self and others, we should thus emphasize their commonality (Gallese, 2001).

Different "mirror matching mechanisms" have been found in monkeys as well as in humans. The same cortical areas - or neurons - are activated during observation of other people's actions and execution of one's own actions (Davidson, 1980; Rizzolatti, Fadiga, Gallese, \& Fogassi, 1996): the supplementary motor area, the dorsal premotor cortex, the supramarginal gyrus, and the superior parietal lobe. In other words, performing an action and observing it are neutral with respect to the agent given that they both activate the same internal motor representation. The fact that action representations are shared in terms of cortical activation is intimately related to the question of agency and raises - as much for the philosopher as for the neurophysiologist - a basic problem that one cannot elude: how can the subject discriminate between internal and external sources of the activated representation?

The shared representations of action are called "pragmatic" (Jeannerod, 1994). They encode the properties of the motor system for optimization of action execution, as well as the properties of the object relevant for the interaction between the agent and the object. Thus, they do not involve the semantic description of the object, of the body and of the movement from a third person perspective; rather they represent actions from the first-person point of view of the agent in interaction with the world. Nonetheless, first-person perspective does not imply that the agent of the action is oneself. Indeed, the activation of shared representations does not suffice by itself to determine who is moving, because their content does not specify the agent. It does not mean that there is no room for the parameter of the agent. By definition, an action involves an agent performing that action, but we may suggest that the parameter of the agent is left indeterminate at this primary level (" $x$ is moving"). That's why we need an additional mechanism that enables us to fulfill the parameter and to self-attribute our own actions: the "Who" system (Georgieff \& Jeannerod, 1998).

This mechanism is most of the time reliable and we usually know without ambiguity who the agent is even in complex situations like mutual imitation. However, it is not infallible: one may mistake one's own actions for those of other people and conversely. First, as we'll see, its sensitivity is limited even in normal subjects and it is possible to self-attribute movements that are 
slightly different from the movement actually performed by oneself. Secondly, the existence of such mechanism involves the possibility of its breakdown, as it is the case in positive symptoms of schizophrenia. During verbal hallucination, schizophrenic people are talking to themselves but they are unaware of doing so. Similarly, in delusions of control may believe that they control the actions performed by someone else or that their own actions are influenced by the will of other people. For example, in the 'alien hand' task, Franck et al. (2001) showed that schizophrenic patients suffer from difficulties correctly attributing the movement that they see: subjects were required to execute hand movements, while the visual feedback they received about the movement was systematically manipulated. A video monitor presented a virtual hand accomplishing either the movement they have made or a movement manipulated by the examiner who introduced an angular or a temporal bias. They were asked whether the movement shown on the screen was their own or not. The results showed that when they were given a weakly biased visual feedback, patients with positive symptoms replied randomly till $300 \mathrm{~ms}$ of delay and $30^{\circ}$ of angular deviation. ${ }^{1}$ Action misattributions are also displayed by apraxic patients (Sirigu, Daprati, PradatDiehl, Franck, \& Jeannerod, 1999) ${ }^{2}$ and by patients suffering from the 'anarchic hand' sign following a lesion in the medial frontal cortex or the corpus callosum (Marchetti \& Della Salla, 1998). In this latter case, patients do not feel that they are initiating or controlling the movements of their anarchic limb, which are frequently at cross-purposes with their verbally stated intentions. All these behaviors might correspond to the disruption of attribution processing. This kind of error seems to be an exaggeration in pathological conditions of what is observed in normal people. In the 'alien hand' task, Franck et al. (2001) revealed indeed that healthy subjects mistakenly self-attributed movements presented with a delay of $150 \mathrm{~ms}$ or a bias of $15^{\circ}$. Do all these errors result from the same failure of a single process? Nothing is less sure. Nevertheless, they show the necessity to assume the existence of one or more cerebral mechanisms that distinguish oneself from the other.

We have briefly described the existence of action representations that do not differentiate between the self and the other. This primary "neutrality" implies the necessity of a specific causal process that disambiguates action representations by articulating who the agent is and that may lead to errors of self-attribution. Therefore, the sense of agency does not result from a constitutive relation between the motor representation from a first person point of view and its self-attribution, but relies on a specific process that needs to be investigated. A theory of action attribution will have to describe which signals are mainly used by the "Who" system and whether they need to be conscious.

\subsection{A cognitive model of agency and schizophrenia}

Two kinds of information are usually available: (i) peripheral information from visual and proprioceptive perception of the moving body and its effects on the environment and (ii) more putative central signals related to action initiation and planning (Desmurget \& Grafton, 2000;

\footnotetext{
${ }^{1}$ We may notice here that these results do not challenge the principle of immunity to error, as the agency judgement is partly based on visual information.

${ }^{2}$ Apraxic patients showed difficulties performing the 'alien hand' task and one patient even commented on her good performance because of the neat movement presented on the screen while she had executed a clumsy one.
} 
Wolpert \& Ghahramani, 2000). This second kind of signals—so called "corollary discharge" or "efference copy" - were independently described in 1950 by three authors, Holst, Mittelstaedt, and Sperry. The latter showed that each time a motor command is issued to make an ocular movement, a copy of this information is produced in parallel and sent to a monitoring system to be compared with the sensory feedback. Then, the confrontation of these two sources of information allows us to distinguish between the active movements and the passive movements imposed by the environment. By extension, Feinberg (1978) and after him Frith (1992) suggested that this central signal represents a kind of internal labeling of our own actions and that its disruption would explain some xenopathic experiences found in schizophrenia. Following Malenka, Angel, Hampton, and Berger (1982), Frith and Done (1989) revealed that schizophrenic patients suffering from delusions of control showed difficulties correcting errors produced during the execution of a movement directed toward a target in displacement without any visual feedback. They explained this result by the fact that schizophrenics could not consciously "read" the efference copy of the motor command. Consequently, they would rely only on peripheral information for action monitoring and self-attribution. Without the awareness of the intention, they misattribute their own actions and interpret them by default as the result of an external source.

Integrating the notion of internal models of action developed by computational studies (Wolpert, Ghahramani, \& Jordan, 1995), the last version of Frith's model combines two internal processes: the inverse model simulates the execution of action and the forward model anticipates the sensory feedback (Frith, Blakemore, \& Wolpert, 2000). The intended, the predicted and the actual states are compared with each other. In addition, we need to postulate another matching system that compares the different kinds of sensory information, and more particularly visual and proprioceptive inputs. These comparators allow refining the inverse and the forward models in case of discrepancies. They also play a major role in action attribution and the disruption of the forward model leads to xenopathic experiences. Delusions of control result from the lack of awareness of the predicted limb position. The patient is conscious of his intention, but not of the sensory consequences of the action as if he had not initiated it: he is deprived of the sense of agency.

Through Frith's theory, two main hypotheses about the sense of agency appear:

1. Hypothesis of action monitoring: the sense of agency results from the control of action. Consequently, delusions of control arise through a deficit of action monitoring.

2. Hypothesis of action awareness: the sense of agency depends on the awareness of endogenous information such as the intended state or the predicted state. Consequently, delusions of control result from the lack of action awareness.

However, both hypotheses raise several problems.

\subsubsection{Hypothesis of action monitoring}

We can wonder how far clinical symptoms are correlated to cognitive deficits, and more exactly xenopathic experiences to a failure of the forward model. If the sense of agency depends solely on the integrity of the forward model, we should systematically find a disruption of this process in patients with xenopathic experiences, which does not seem to be the case. Contrary to Frith's prediction, patients with positive symptoms are not more affected by errors of correction than patients with negative symptoms (Leudar, Thomas, \& Johnston, 1994). Moreover, using 
the same task as Frith and Done (1989), Kopp and Rist (1994) found no more errors of correction in the schizophrenic population than in the control one. Similarly, Trillenberg et al. (1998) analyzed the ocular smooth pursuit response to a sinusoidally moving target that was suddenly stopped after some cycles of regular movements: schizophrenic patients were able to visually keep track and anticipate the target position. More recently, in a sensori-motor adjustment task, Fourneret, Franck, Slachevsky, and Jeannerod (2001) showed that schizophrenic patients, especially those suffering from positive symptoms, corrected an angular perturbation in the absence of visual feedback as well as the control subjects. Therefore, schizophrenic patients show an overall preserved ability to monitor their own actions, to predict their sensory consequences and to compare their predictions with the intended state and the sensory feedback (see Fig. 1).

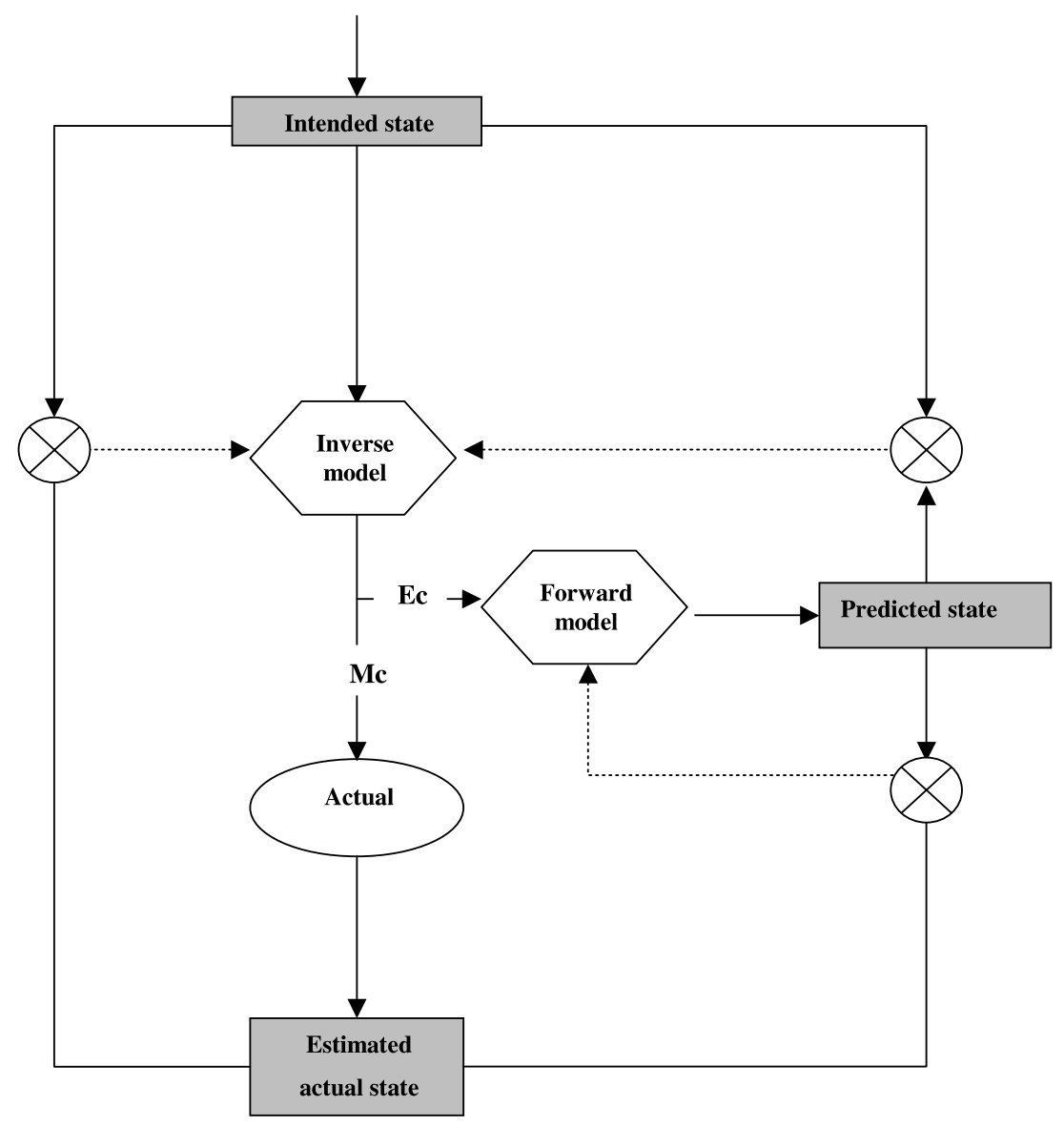

Fig. 1. Frith's model. The inverse model combined with the actual sensory feedback gives rise to the estimated actual state, which is compared to the intended state. The estimated actual state is also compared to the predicted state that results from the forward model. Finally, the intended state is compared to the predicted state. These comparators allow to refine the inverse and the forward model in case of discrepancies. According to Frith, they also play a role in the attribution of action (Mc, Motor commands; Ec, Efference copies). 


\subsubsection{Hypothesis of action awareness}

Rather than a deficit of the forward model, delusions of control would then result from a disruption of the awareness of the predicted state. According to Frith et al. (2000), action control uses egocentric action representations whereas the sense of agency depends on representations from a third person point of view. Schizophrenic patients would then have difficulties switching the referential coordinates of actions. However, Fourneret et al. (2001) showed that most of the patients with positive symptoms were able to report their actual strategy for compensating the bias. Thus, in some circumstances, they could consciously monitor their actions. Moreover, the sense of agency cannot depend on the awareness of the forward model, as most of the time we do not consciously control our actions and we are not aware of the predicted states. On the contrary, most of our actions are automatic and Frith et al. (2000) acknowledged that action could be monitored in the complete lack of awareness. For instance, Castiello, Paulignan, and Jeannerod (1991) showed that an unexpected target jump becomes available to consciousness $200 \mathrm{~ms}$ after the sensori-motor adjustment. Visual representations used for action are indeed distinct from conscious representations used for identification (Milner \& Goodale, 1995). It has also been demonstrated that we have a limited awareness of our own motor representations (Fourneret \& Jeannerod, 1998). Most of the time, we are only conscious of the general goal of the action and the visual feedback of the execution, but the specific parameters of the way we have accomplished the action is unavailable to awareness. Actions are indeed not represented in the same way at the automatic and at the conscious levels. At the automatic level, the succession of specific movements is described in all the relevant details for the motor system ("I stretch my arm with an angle $x$, a strength $y$ and a grip aperture w"). However, I am not conscious of the angle of my arm, nor of the grip aperture. Rather, I recognize a conscious global goal as mine ("I grasp the glass"). If the sense of agency solely depended on the process of conscious motor representations, then I could self-attribute someone else's action simply because both of our actions share the same goal, even if they do not share the specific movements performed to reach the goal. The "Who" system would then not be reliable as conscious action representations of action are not fine-grained enough to disambiguate situations such as mutual imitation. Therefore, the sense of agency arises through the processing of unconscious signals that are fine-grained enough for determining the agent in social interaction. According to Jeannerod (forthcoming), this is one of the paradoxes of motor cognition:

Whereas subjects execute actions, the content of which they remain essentially unaware, they seem to have no problem in correctly attributing these actions to themselves or to an external agent.

Thus, we cannot assume a systematic deficit of action control in schizophrenic patients; neither can we directly relate the presence of positive symptoms solely to a specific impairment of action awareness. Rather than postulating a complete and permanent disruption of action monitoring, we prefer to suggest that the integrity of this system is probably overall preserved, except in certain circumstances still to be defined. Furthermore, far from feeling constantly alienated, most of the time schizophrenic patients do correctly self-attribute their own actions and thoughts and xenopathic experiences are only occasional. That's why we suggest that the current challenge is in priority to understand why action attribution episodically fails and why its deficiency may correspond to specific semantic contents (aggressive, violent...). The hypothesis of contextual information processing impairments in schizophrenia offers the advantage of providing an 
explanation of the non-systematicy of both errors of action control and xenopathic experiences (Cohen \& Servan-Schreiber, 1992; Cohen, Barch, Carter, \& Servan-Schreiber, 1999; Hemsley, 1992). Several schizophrenic performance deficits may be related to a central disturbance in maintaining the internal representation of contextual information over time and in using that information to inhibit inappropriate responses. In this theoretical framework, we may suggest that self-attribution disorders are the result of the deficit of the processing of relevant contextual information that is necessary to disambiguate problematic social and communicative situations. ${ }^{3}$

According to Shoemaker's theory of self-knowledge, the consciousness of the action should be equivalent to its self-attribution. The gap between oneself and the other would indeed be such that they could never be confused. However, we contend that the sense of agency does not result from a constitutive relation between the representation of actions from a first-person point of view and their self-attribution, but rather relies on a specific system dedicated to action attribution. Two intimately related kinds of empirical results tend to argue in this direction: the existence of mirror matching systems and the possibility of errors of action attribution. First, we have seen that motor representations are neutral in respect to the agent in the sense that one similarly represents oneself and the other from a first-person perspective. We are thus able to represent someone else's actions "as if they were our own" (Ayer, 1963) by the sharing of representations common to action and perception. The primary lack of differentiation implies the necessity of a specific causal process that disambiguates the representations by articulating who the agent is. Furthermore, xenopathic experiences in schizophrenia as well as errors of action attribution in normal subjects under ambiguous conditions reveal that we do not infallibly determine who the agent is. Even if we have to be cautious in the interpretation of these errors, which cannot be so easily reduced to deficit of action monitoring or to lack of action awareness, they illustrate the possible disconnection between the direct consciousness of one's own actions ("Someone is moving," while I am moving) and the consciousness of actions as one's own ("I am moving"). Therefore, the possibility of errors of action attribution confirms the existence of an attribution mechanism that can breakdown. Consequently, we have to acknowledge the necessity of a "Who" system based on the interaction between intentions, expectations and sensory feedback. In order to investigate more precisely its nature, we still need to refine the definition of the sense of agency and to establish the taxonomy of the different levels of action representations.

\section{Toward a theory of action attribution}

Through the analysis of the possible deficits underlying positive symptoms in schizophrenia, we have shown that the sense of agency cannot be reduced to action control or to action awareness and that we need to distinguish three levels functionally independent even if intimately related (Proust, 2000). On the one hand, the mechanisms of action monitoring are automatic, efficient, fast and anticipatory. On the other hand, the consciousness of the specific parameters of movements is limited and the subject has mainly access to the content of the voluntary prior intention and the visual feedback. We suggest that self-attribution of action is at the junction point of both

\footnotetext{
${ }^{3}$ For more details, see Bazin, Perruchet, Hardy-Bayle, and Feline (2000).
} 
levels. First, it is distinct from action awareness because we do not need to be conscious of the action in order to recognize it as ours. Secondly, it does not completely merge with action monitoring. Indeed, motor control can be understood in terms of engineering systems, but although a thermostat works in the same way as the motor system, it does not self-attribute the modification of the surrounding temperature. Thus, action attribution constitutes an additional dimension and takes place in the social frame of reference of shared representations between self and others, rather than in the solipsist frame of reference of motor control (Georgieff \& Jeannerod, 1998). Nevertheless, through control and initiation, we discover ourselves as their causal source of the executed actions.

\subsection{The dual sense of agency}

In the causal theory of action, as it has been defended by Decety et al. (1994), actions are distinct from other events in virtue of their causal antecedents. The sense of agency is thus intimately related with the sense of causality and satisfies the same kinds of criterion: Priority, consistency and exclusivity (Michotte, 1963; Wegner, 2002). For instance, we perceive a causal relation between the movement of two billiard balls A and B if the movement of B starts just after the hit (criterion of priority), if the direction of the movement matches with the impulse given by A (criterion of consistency) and if no other event can explain it (criterion of exclusivity). Similarly, Franck et al. (2001) showed the importance of temporal priority and consistency in the experience of agency: As we have previously said, normal subjects did not self-attribute movements visually presented with a delay of more than $150 \mathrm{~ms}$ or with an angular deviation of more than $15^{\circ}$ by comparison with their own movements. ${ }^{4}$ Furthermore, Haggard, Aschersleben, Gehrke, and Prinz (2002) revealed the existence of a temporal attraction of the action towards its cause. Subjects were required to estimate the perceived time of stimuli (beeps) and of actions (keypresses). There were strong perceptual attraction effects between percepts of the two events, by comparison to the perceived times of stimuli or actions made in isolation: The causal event in each contingent task was perceived to occur at its normal time, whereas the consequent event was biased towards the cause. Therefore, the awareness of the effect is temporally attracted toward its cause. According to the authors, the experience of agency results from the "intentional binding" between intentions, actions and sensory feedback, which are attracted toward each other, reinforcing the perception of their causal relations..$^{5}$

Therefore, in order to understand actions, we need to analyze their causal antecedents, that is, what initiates the occurrence of the action ("why I do move, rather than doing nothing") and

\footnotetext{
${ }^{4}$ Blakemore, Frith, and Wolpert (1999) also emphasized the role of temporal priority in the experience of tickling. The intensity of the tickling sensation is increased when someone else tickles us, in comparison with the felt sensation when we tickle ourselves. If there is an artificial delay between the tactile stimulation and the self-generated movement, the perceived intensity of the stimulation increases because the movement is attributed to someone else.

${ }^{5}$ One of the main unresolved questions in neuroscience is how information can be integrated into a coherent representation (John, 2001; Singer, 2001). In order to solve this "binding problem," it has been suggested that appropriate synchronization among cortical systems may be one of the necessary conditions for the buildup of perceptual states and conscious awareness. By extension, Haggard et al. (2002) suggested that this synchronization process could make possible causal judgments about actions, by creating a temporal binding between the initial intention and the action.
} 
what specifies the content of the action ("why I move this way"). Actions are not only preceded by a "prior intention" independent of the execution, they are also continuously represented in the "intention in action" till the end of the action by integrating internal and external changes (Searle, 1983). The sense of agency is not the experience of an act of will distinct from bodily movements; it is the experience of the "on line" control of action execution. Therefore, we have to distinguish between two aspects: I am the cause of the initiation of the action and I am the cause of the way the action is achieved. In the former case, I am able to say "I move" independently of the specific movement executed, while in the latter case, I am able to say "this is my movement," recognizing the specific parameters of the performed action. This conceptual analysis does not result only from armchair speculations and philosophical ruminations, but also from empirical dissociations found in neuropsychology: Anosognosic patients display a disruption of the sense of initiation, while deafferented patients suffer from a deficit of the sense of one's own movements. For instance, anosognosic patients believe that they have raised their hand while actually they are unable to make any movement because of their paralysis (Feinberg, 2001, p. 23):

Feinberg: Now raise you left arm please. [No movement, no response; left hand remains paralyzed on the bed, on the patient's left side].

Feinberg: Where is your left arm now?

Rodney: Up in the air.

Feinberg: It's up in the air? How high is it now about?

Rodney: Not too high.

Feinberg: Not too high? [Patient is asked to point to his left arm. With his right hand he points two and a half feet above the bed]. Okay, good put your right arm down, now. Put your left arm down. Now, where is your left arm? [Patient points to his left arm on the bed].

According to Heilman, Barrett, and Adair (1998), anosognosic patients do not even try to initiate any action and thus, they do not send any efference copy that could be compared to sensory feedback and that would inform them that the intended movement has not been performed. Gold, Adair, Jacobs, and Heilman (1994) showed indeed a hypoactivity of premotor processing linked to a loss of motor intentions in anosognosia. Subjects were required to squeeze a dynamometer with each hand. When the patient suffering from anosognosia squeezed with his normal hand, both the right and the left pectoralis contracted. But when asked to squeeze with the contralesional hand, he did not contract either pectoralis muscle. Therefore, even if the movement-or at least the required muscle contractions-could still be triggered automatically, the patient was no longer able to voluntarily initiate a movement. However, he was not conscious of this deficit and felt as if he were really initiating the movement when he wanted. We can thus conclude that anosognosia is associated to the disruption of the sense of initiation. On the contrary, the sense of initiation is preserved in deafferented patients, but not the sense of one's own movements. For instance, following a neuropathy G.L. has been deafferented below the mouth, that is, she does not receive any tactile and proprioceptive information on her body: if she closes her eyes, she does not know her bodily position and she has learnt to visually control her movements (Cole \& Paillard, 1995). In a recent study with this patient using the 'alien hand' task, Farrer et al. (personal communication) also revealed that she self-attributed visually presented movements even if the 
visual feedback was strongly biased. However, she perfectly knew that she was moving: She did not pretend to have moved while she did not, like anosognosic patients, nor did she make the same movement twice believing that she had not moved yet. Therefore, the sense of initiation is preserved whereas the sense of one's own movements is impaired. In summary, these two pathological phenomena tend to indicate that the sense of initiation and the sense of one's own movements constitute two independent aspects of self-consciousness, which can be specifically impaired. ${ }^{6}$

\subsection{Back to Frith's model}

At a more operative level, we may speculate that these two kinds of sense of agency result from different cognitive mechanisms. Frith's model of action monitoring assumes the existence of different comparators, which combine the intended state, the predicted state and the actual state. Gallagher (2000) suggested applying the distinction between the sense of agency and the sense of ownership on this model. Briefly, he considered that I self-attribute a movement either because I am the cause of the movement (sense of agency) or because I am the body which is performing the movement (sense of ownership). In this conceptual framework, the sense of agency - which is not analyzed into the sense of initiation and the sense of one's own movements - depends solely on the comparison between the intention and the predicted state. Therefore, the sense of agency would be disconnected from the actual execution of the movement, independent from any sensory feedback. On the contrary, the sense of ownership would result from the comparison between the predicted state and the sensory feedback. However, such mechanism cannot give any account of the sense of ownership of one's own body in passive movements: as there is no predicted state, the discrepancy with the sensory feedback of the actual movement should lead the subject to deny the ownership of the moving body. Furthermore, I do not need to move my body in order to recognize it as mine. The sense of ownership of one's own body cannot thus be solely understood in terms of action monitoring. It raises its own problems, independent from the question of action attribution. Consequently, we suggest focusing only upon the sense of agency and its two distinct aspects.

The sense of initiation of the action is prior to its execution and does not depend on any sensory feedback. Indeed, Libet (1985) asked subjects to estimate the time at which they initiated a finger movement and showed that the reported time of action awareness anticipated the actual starting time of the action by $80 \mathrm{~ms}$. In other words, I am aware that I move before I actually move. According to Frith et al. (2000), this judgement is related to the predicted state of the system. Nonetheless, it does not mean that we are conscious of the content of the predicted state, as if we were able to directly "read" the endogenous signal. Rather, only the occurrence of the predicted state and the result of its comparison with the intended state are available to awareness. That's why we suggest that the matching between the intended and the predicted states constitutes the basis of the experience of initiating the action and does not allow

\footnotetext{
${ }^{6}$ However, they do not illustrate a double dissociation. Indeed, we cannot determine the integrity of the sense of one's own movements in anosognosia as no movement is actually performed.
} 
recognizing the perceived executed movement as the result of one's own intentions. ${ }^{7}$ Unlike Gallagher (2000), we thus consider that the sense of agency is not exhausted by this first kind of comparison. The sense of agency is indeed not totally independent from sensory information. In order to recognize the movement reflected by a mirror as mine, I need to compare what I see with what I do. This kind of matching is also involved in the 'alien hand' task and the fact that G.L. was not able to identify her own movements demonstrates that we need proprioceptive and visual information for the sense of one's own movements. Similarly, Blakemore et al. (1999) emphasized the major role played by the sensory feedback in the sense of agency. Thus, the comparison between the predicted state and the sensory feedback provides the sense of one's own movements, rather than the sense of ownership.

\subsection{Possible neural bases of the sense of agency}

Finally, we may formulate some hypothesis about the possible neural bases of the sense of agency. We have argued for the necessity of the "Who" system from the existence of neural overlapping during action observation and action execution. However, the overlap is only partial and some specific areas are activated solely for self-produced actions. Therefore, Georgieff and Jeannerod (1998) postulated that the activation of non-overlapping areas allows distinguishing between one's own actions and someone else's actions. Recent data suggest indeed that action attribution involves the activation of a vast cortical network including the prefrontal and the parietal cortex, the supplementary motor area (SMA) and the cerebellum (Decety \& Grezes, 1999; Grezes \& Decety, 2001; Vogeley \& Fink, 2003).

Fink et al. (1999) using a mirror device to manipulate the visual feedback of the executed movements showed a specific activation in the right dorsololateral prefrontal cortex when a conscious conflict was generated between intention and the perceptual consequences. In its unique capability of integrating external and internal data, the prefrontal cortex appears to be an essential component of the neural implementation of the intended state. The cerebellarparietal network seems also to play a key role in the neural mechanisms underlying agency judgements. Farrer et al. (2003) revealed that in the 'alien hand' task, the degree of discrepancy between the performed movement and the visually presented movement modulated the activity of the anterior insula and the inferior part of the parietal lobe, specifically on the right side. In accord with previous studies (Farrer \& Frith, 2002), the results showed that being aware of causing an action was associated with a greater activation in the anterior insula, whereas attributing the action to another person was associated with a greater activation in the inferior parietal cortex. Similarly, Ruby and Decety (2001) reported that the simulation of action from third-person perspective recruited right inferior parietal when compared to the simulation from a first-person perspective. They thus suggested that the right inferior parietal lobe as well as in precuneus and somatosensory cortex are involved in action attribution. Furthermore, when hypnosis was used to induce action misattributions in normal subjects, movements attributed to

\footnotetext{
${ }^{7}$ One may wonder whether the existence of the "Who" system does not lead to an infinite regress. For instance, in order to know whether this action is mine I would need first to determine that the intended state is mine. This problem indeed arises only if we consider that mental states, such as intentions, also need to be self-attributed, as Frith (1992) sustained. We assume here that self-attribution of intentions cannot be understood in terms of efference copies.
} 


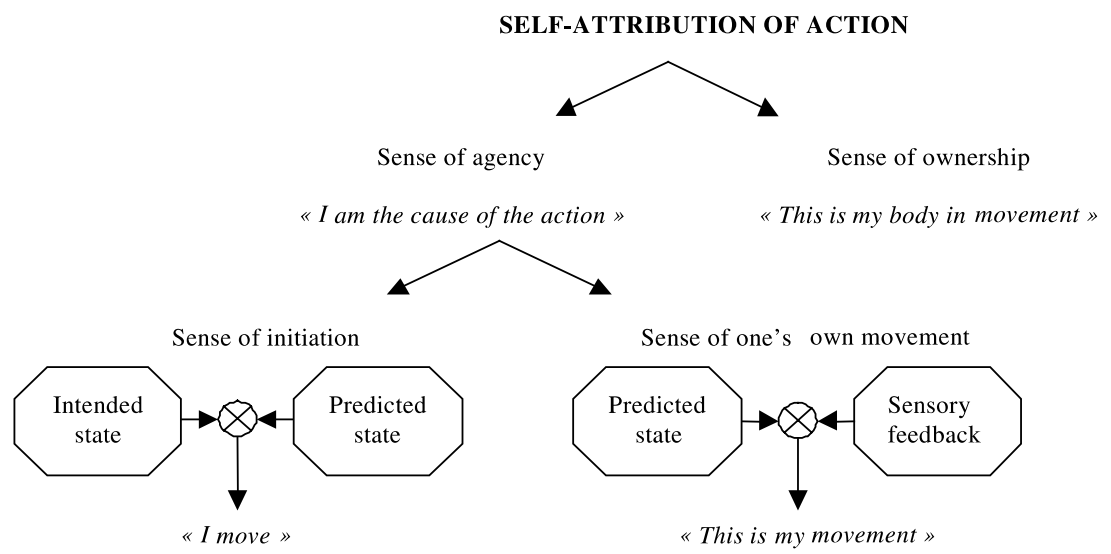

Fig. 2. Self-attribution of action. A body in movement may arise different kinds of I-thoughts: (i) "my body is moving," that is, the sense of ownership that results from the consciousness of oneself as the owner of the body in movement; (ii) "I move," that is, the consciousness of oneself as the cause of the action initiation; (iii) "this is my movement," that is, the consciousness of oneself as the cause of the specific parameters of the movement. However, self-attribution of action derives only indirectly from the sense of ownership, which is a matter of body recognition, rather than action recognition. On the contrary, the sense of inititation and the sense of one's own movements may be related to the underlying action monitoring. Yet, we should not preclude the influence of higher levels information such as the context and the subject's beliefs.

an external source resulted in significantly higher activations in the parietal cortex and the cerebellum, than movements correctly self-attributed (Blakemore, Oakley, \& Frith, 2003). Consistently, schizophrenic patients suffering from delusions of control revealed an overactivation of the right parietal cortex (Spence et al., 1997). Moreover, the Schneiderian score of eighty-seven patients (including delusion of thought insertion, auditory-verbal hallucinations, delusion of reference and delusion of control) was positively correlated with the regional cerebral blood flow (rCBF) in the right superior parietal cortex and negatively correlated with the rCBF in the left posterior cingulate gyrus and in the left lingual gyrus (Franck, O'Leary, Flaum, Hichwa, \& Andreasen, 2002).

Consequently, we may postulate that the sense of initiation derives from the interaction between the anterior brain regions (prefrontal cortex), the posterior ones (specifically the parietal cortex) and the cerebellum, whereas the sense of one's own movement would involve the parietal cortex and the cerebellum, as neural comparators, and the perceptual areas (see Fig. 2).

\section{Bottom-up and top-down interpretations of agency}

In summary, the double sense of agency depends on the same mechanisms as action control: it results from the unconscious comparison between different kinds of afferent and efferent signals. Therefore, these monitoring systems allow one to automatically distinguish one's own actions and those of the other. For example, ocular movements are systematically attributed independently of the awareness of these movements. Thus, on the one hand, action attribution does not use conscious information about action and on the other hand, it is systematic even in complete lack of action awareness: unconscious actions are not anonymous. As Russell (1996, p. 263) said: 
Action-monitoring is a subpersonal process that enables the subjects to discriminate between self-determined and world-determined changes in input. It can give rise to a mode of experience (the experience of being the cause of altered inputs and the experience of being in control), but it is not itself a mode of experience.

This unconscious label is prior to the sense of agency. However, can we reduce the latter to the former? In other words, does the sense of agency reflect the awareness of the automatic label or does it integrate other kinds of information?

Even if the sense of agency arises through the process of unconscious motor representations, some higher-order information may interfere, like the context and the subject's reasoning processing. According to Stephens and Graham (2000), self-attribution results from the intentional stance and corresponds to the integration of the mental and bodily states in the narrative fiction that we're constructing about ourselves. They interpreted auditory hallucinations in schizophrenia as the loss of the sense of the unity of the self. In other words, the content of what the "voice" says does not fit with the story about the subject and thus is projected to an external agent. Similarly, Wegner (2002) described several "paranormal" phenomena such as automatic writing and spirit possession that may be interpreted as high-level misattribution of action. He also reported the effect of subliminal presentation of the word "I" or "me" on judgments of authorship. Subjects were required to judge letter strings to be words or not and the screen went blank after each trial either because subjects replied correctly or the computer did it; then they were asked who did it. On trials with subliminal priming, they tended to self-attribute the ambiguous action. These examples reveal that we can infer that we are not the agents of our own actions at higher cognitive levels, while there is no deficit at the subpersonal level of action monitoring. ${ }^{8} \mathrm{We}$ may also imagine the reverse: If the automatic action attribution does not work, the motor system refers the action to another agent at the subpersonal level; but at the conscious level, I may believe that I am the agent of that action, because I take into account the fact that I am alone. Thus, we can consciously recognize actions as our own without self-attributing them at the subpersonal level and vice-versa. We may even imagine that both levels are disrupted. For instance, Langdon and Coltheart (2000) argued that aberrant perceptual experiences do not suffice to explain delusions, such as schizophrenic ones, and that we need to postulate an additional deficit at the level of the rational evaluation of one's own beliefs. Consequently, we have to take into account different levels of self-consciousness, which can be reduced neither to subpersonal mechanisms of action monitoring, nor to the result of inferences and beliefs.

\section{Conclusion}

It seems that I am immediately aware that I am moving and that the sense of agency derives directly from the consciousness of actions. However, this is a phenomenological illusion. The sense of agency relies on a prior differentiation between oneself and the other. This distinction

\footnotetext{
${ }^{8}$ Wegner (2002) seems to take into account only this hypothesis and considers that we always need to "infer" that we are the cause of our own actions.
} 
depends on a specific system of self-attribution, the "Who" system, which takes place in a social frame of reference of shared representations between self and others. The sense of agency must be considered as a functional level distinct from the mechanisms of action control and action awareness. The questions concerning the nature of the links unifying these three levels and their implications in the construction of the self are still open. We do not pretend to provide here the key of self-consciousness. Nevertheless, the different theoretical and empirical approaches that we presented have allowed us to shed a new light on the model of agency proposed by Frith and collaborators, as well as to refine the notion of the sense of agency itself. The empirical studies of the relationship between perception of action and self-awareness are fundamental: they contribute to the understanding of the cognitive mechanisms underlying the notion of agency and their possible disruptions, while stimulating and renewing the philosophical reflection about the self.

\section{Acknowledgments}

We would like to thank Marc Jeannerod and Pierce Jacob for their constant support. We are also grateful to the reviewers for their helpful comments.

\section{References}

Ayer, A. J. (1963). Privacy. In The concept of a person and other essays (pp. 52-81). New York: St. Martin's Press.

Bazin, N., Perruchet, P., Hardy-Bayle, M. C., \& Feline, A. (2000). Context-dependent information processing in patients with schizophrenia. Schizophrenia Research, 29, 93-101.

Blakemore, S., Frith, C., \& Wolpert, D. (1999). Spatiotemporal prediction modulates the perception of self produced stimuli. Journal of Cognitive Neuroscience, 11, 551-559.

Blakemore, S. J., Oakley, D. A., \& Frith, C. D. (2003). Delusions of alien control in the normal brain. Neuropsychologia, 41, 1058-1067.

Bisiach, E., Rusconi, M. L., \& Vallar, G. (1991). Remission of somatoparaphrenic delusion through vestibular stimulation. Neuropsychologia, 29, 1029-1031.

Bottini, G., Bisiach, E., Sterzi, R., \& Vallar, G. (2002). Feeling touches in someone else's hand. Neuroreport, 13, 249-252.

Castiello, U., Paulignan, Y., \& Jeannerod, M. (1991). Temporal dissociation of motor responses and subjective awareness. A study in normal subjects. Brain, 114, 2639-2655.

Cohen, J. D., \& Servan-Schreiber, D. (1992). Context, cortex, and dopamine: A connectionist approach to behavior and biology in schizophrenia. Psychological Review, 99, 45-77.

Cohen, J. D., Barch, D. M., Carter, C., \& Servan-Schreiber, D. (1999). Context-processing deficits in schizophrenia: Converging evidence from three theoretically motivated cognitive tasks. Journal of Abnormal Psychology, 108, $120-133$.

Cole, J., \& Paillard, J. (1995). Living without touch and peripheral information about body position and movement: studies with deafferented subjects. In J. L. Bermudez, A. Marcel, \& N. Eilan (Eds.), The body and the self. Cambridge, MA: MIT Press.

Davidson, D. (1980). Essays on Actions and Events. Oxford: Oxford University Press.

Decety, J., Perani, D., Jeannerod, M., Bettinardi, V., Tadary, B., Woods, R., Mazziotta, J. C., \& Fazio, F. (1994). Mapping motor representations with PET. Nature, 371, 600-602.

Decety, J., \& Grezes, J. (1999). Neural mechanisms subserving the perception of human actions. Trends in Cognitive Sciences, 3, 172-178. 
Desmurget, M., \& Grafton, S. (2000). Forward modeling allows feedback control for fast reaching movements. Trends in Cognitives Sciences, 11, 423-431.

Evans, G. (1982). In J. MacDowell (Ed.), The varieties of reference. Oxford: Oxford University Press.

Farrer, C., \& Frith, C. D. (2002). Experiencing oneself vs another person as being the cause of an action: The neural correlates of the experience of agency. Neuroimage, 15(3), 596-603.

Farrer, C., Franck, N., Georgieff, N., Frith, C. D., Decety, J., \& Jeannerod, M. (2003). Modulating the experience of agency: A positron emission tomography study. Neuroimage, 18(2), 324-333.

Feinberg, I. (1978). Efference copy and corollary discharge: Implications for thinking and its disorder. Schizophrenia Bulletin, 4, 636-640.

Feinberg, T. E. (2001). Altered Egos. New York: Oxford University Press.

Fink, G. R., Marshall, J. C., Halligan, P. W., Frith, C. D., Driver, J., Frackowiak, R. S., \& Dolan, R. J. (1999). The neural consequences of conflict between intention and the senses. Brain, 122, 497-512.

Fourneret, P., \& Jeannerod, M. (1998). Limited conscious monitoring of motor performance in normal subjects. Neuropsychologia, 36(11), 1133-1140.

Fourneret, P., Franck, N., Slachevsky, A., \& Jeannerod, M. (2001). Self-monitoring in schizophrenia revisited. Neuroreport, 12(6), 1203-1208.

Franck, N., Farrer, C., Georgieff, N., Marie-Cardine, M., Daléry, J., d'Amato, T., \& Jeannerod, M. (2001). Defective recognition of one's own actions in patients with schizophrenia. American Journal of Psychiatry, 158, 454-459.

Franck, N., O'Leary, D. S., Flaum, M., Hichwa, R. D., \& Andreasen, N. C. (2002). Cerebral blood flow changes associated with Schneiderian first-rank symptoms in schizophrenia. Journal of Neuropsychiatry and Clinical Neurosciences, 14, 277-282.

Frith, C. D. (1992). The cognitive neuropsychology of schizophrenia. Hove: Erlblaum.

Frith, C. D., \& Done, D. J. (1989). Experiences of alien control in schizophrenia reflect disorder in the central monitoring of action. Psychological Medicine, 19, 359-363.

Frith, C. D., Blakemore, S., \& Wolpert, D. (2000). Abnormalities in the awareness and control of action. Philosophical Transactions of the Royal Society of London, 355, 1771-1788.

Gallagher, S. (2000). Philosophical conceptions of the self: Implications for cognitive science. Trends in cognitive sciences, 4(1), 14-21.

Gallese, V. (2001). The 'Shared Manifold' hypothesis: From mirror neurons to empathy. Journal of Consciousness Studies, 8(5-7), 33-50.

Georgieff, N., \& Jeannerod, M. (1998). Beyond consciousness of external reality: A "Who" system for consciousness of action and self-consciousness. Consciousness and Cognition, 7, 465-477.

Gold, M., Adair, J. C., Jacobs, D. H., \& Heilman, K. M. (1994). Anosognosia for hemiplegia: An electrophysiologic investigation of the feed-forward hypothesis. Neurology, 44(10), 1804-1808.

Gopnik, A., \& Meltzoff, A. (1994). Minds, bodies and persons: Young children's understanding of the self and others as reflected in imitation and "theory of mind" research. In S. Parker, \& R. Mitchell (Eds.), Self-awareness in animals and humans. New York: Cambridge University Press.

Grezes, J., \& Decety, J. (2001). Functional anatomy of execution, mental simulation, observation, and verb generation of actions: A meta-analysis. Human Brain Mapping, 12, 1-19.

Haggard, P., Aschersleben, G., Gehrke, J., \& Prinz, W. (2002). Action, binding and awareness. In W. Prinz, \& B. Hommel (Eds.), Attention and Performance (Vol. XIX). Common mechanisms in perception and action. Oxford: Oxford University Press.

Heilman, K. M., Barrett, A. M., \& Adair, J. C. (1998). Possible mechanisms of anosognosia: A defect in self-awareness. Philosophical Transactions of the Royal Society of London, 353(1377), 1903-1909.

Hemsley, D. R. (1992). Cognitive abnormalities and schizophrenic symptoms. Psychological Medicine, 22(4), 839-842. Hume, D. (1739). A treatise of human nature. Oxford: Clarendon Press.

Jeannerod, M. (1994). The representing brain. Neural correlates of motor intention and imagery. The Behavioral and Brain Sciences, 17, 187-245.

Jeannerod, M. (forthcoming). Consciousness of action and self-consciousness: A cognitive neuroscience approach. In: J. Roessler, N. Eilan (Eds.), Agency and self-awareness: Issues in philosophy and psychology. Oxford: Oxford University Press. 
John, E. R. (2001). A field theory of consciousness. Consciousness and Cognition, 10, 184-213.

Kopp, B., \& Rist, F. (1994). Error-correcting behavior in schizophrenics patients. Schizophrenia Research, 13, 11-22. Langdon, R., \& Coltheart, M. (2000). The cognitive neuropsychology of delusions. Mind and Language, 15(1), 184-218.

Leudar, I., Thomas, P., \& Johnston, M. (1994). Self-monitoring in speech production: Effects of verbal hallucinations and negative symptoms. Psychological Medicine, 24(3), 749-761.

Lhermitte, F., Pillon, B., \& Serdaru, M. (1986). Human autonomy and the frontal lobes: I. Imitation and utilization behavior: A neuropsychological study of 75 patients. Annals of Neurology, 19, 326-334.

Libet, B. (1985). Unconscious cerebral initiative and the role of conscious will in voluntary action. The Behavioral and Brain Sciences, 8, 529-566.

Malenka, R. C., Angel, R. W., Hampton, B., \& Berger, P. A. (1982). Impaired central error-correcting behavior in schizophrenia. Archives of General Psychiatry, 39, 101-107.

Marchetti, C., \& Della Salla, S. (1998). Disentangling the alien and the anarchic hand. Cognitive neuropsychiatry, 3(3), 191-207.

Meltzoff, A. N., \& Moore, M. K. (1995). Infant's understanding of people and things: From body imitation to folk psychology. In J. L. Bermudez, A. Marcel, \& N. Eilan (Eds.), The body and the self. Cambridge, MA: MIT Press.

Melzack, R. (1992). Phantom limbs. Scientific American, 266(4), 120-126.

Michotte, A. (1963). The Perception of Causality. New York: Basic Books.

Milner, D., \& Goodale, M. A. (1995). The visual brain in action. New York: Oxford University Press.

Proust, J. (2000). Awareness of agency: Three levels of analysis. In T. Metzinger (Ed.), The neural correlates of consciousness. Cambridge, MA: MIT Press.

Rizzolatti, G., Fadiga, L., Gallese, V., \& Fogassi, L. (1996). Premotor cortex and the recognition of motor actions. Cognitive Brain Research, 3, 131-141.

Ruby, P., \& Decety, J. (2001). Effect of subjective perspective taking during simulation of action: A PET investigation of agency. Nature Neuroscience, 4, 546-550.

Russell, J. (1996). Agency: Its role in mental development. Hove: Erlbaum.

Searle, J. (1983). Intentionality. Cambridge: Cambridge University Press.

Shoemaker, S. (1963). Self-knowledge and self-identity. Ithaca, NY: Cornell University Press.

Shoemaker, S. (1994). Self-knowledge and "inner sense". Philosophy and Phenomenological Research, LIV, 249-314.

Singer, W. (2001). Consciousness and the binding problem. Annals of the New York Academy of Sciences, 9, 123-146.

Sirigu, A., Daprati, E., Pradat-Diehl, P., Franck, N., \& Jeannerod, M. (1999). Perception of self-generated movement following left parietal lesion. Brain, 122(10), 1867-1874.

Spence, S. A., Brooks, D. J., Hirsch, S. R., Liddle, P. F., Meehan, J., \& Grasby, P. M. (1997). A PET study of voluntary movement in schizophrenic patients experiencing passivity phenomena (delusions of alien control). Brain, 120, 19972011.

Stephens, G. L., \& Graham, L. (2000). When self-consciousness breaks. Cambridge, MA: MIT press.

Trillenberg, P., Heide, W., Junghanns, K., Blankenburg, M., Arolt, V., \& Kompf, D. (1998). Target anticipation and impairment of smooth pursuit eye movements in schizophrenia. Experimental Brain Research, 120(3), 316-324.

Vogeley, K., \& Fink, G. R. (2003). Neural correlates of the first-person-perspective. Trends in Cognitive Sciences, 7 , $38-42$.

Wegner, D. M. (2002). The illusion of conscious will. Cambridge, MA: MIT Press.

Wittgenstein, L. (1958). The Blue and Brown Books. England: Basil Blackwell.

Wolpert, D. M., Ghahramani, Z., \& Jordan, M. I. (1995). An internal model for sensorimotor integration. Science, 269, 1880-1882.

Wolpert, D. M., \& Ghahramani, Z. (2000). Computational principles of movement neurosciences. Nature Neuroscience (Suppl. 3), 1212-1217. 